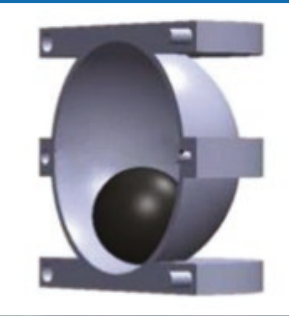

\title{
Materials and approaches for on-body energy harvesting
}

\author{
Shad Roundy and Susan Trolier-McKinstry
}

\begin{abstract}
The human body is a challenging platform for energy harvesting. For thermoelectrics, the small temperature differences between the skin and air necessitate materials with low thermal conductivities in order to maintain useful output powers. For kinetic harvesting, human motion is not strongly tonal, the frequencies are very low, and the accelerations are modest. Kinetic harvesting can be split into two categories - inertial, in which human motion excites an inertial mass-the motion of which is transduced to electricity, and clothing integrated, in which the harvesting material is integrated with a garment or other flexible wearable system. In the first case, key issues are the electromechanical dynamics of the system and materials with improved electromechanical transduction figures of merit. In the second case, materials that provide flexibility, stretchability, and comfort are of primary importance.
\end{abstract}

\section{Introduction}

There has been a recent proliferation of wearable electronics, including health and wellness monitors, ${ }^{1}$ and sensing systems embedded into clothing. ${ }^{2}$ The vast majority of these devices are battery powered. In some cases, this is not a concern, as regular recharging or replacement is not a major inconvenience. However, in other cases, for example, in the case of 24/7 wellness monitoring, it is critical that the sensing systems not have breaks in operation due to lack of power. Breaks in operation can lead to a situation in which health-critical parameters are not being monitored, which can present safety issues for the user. Furthermore, in most cases, removing the need to replace batteries improves the user experience.

In their seminal study, Starner and Paradiso ${ }^{3}$ reviewed human processes that might be tapped for powering wearable or implantable electronics. In the intervening years, there have been many demonstrations of on-body energy harvesters. The most prevalent targeted sources of energy are upper body motion, ${ }^{4-6}$ thermal gradients, ${ }^{7-9}$ and heel strike (or shoeintegrated harvesters). ${ }^{10-12}$

This article synthesizes recent work on energy harvesting for wearables, focusing on a discussion of system considerations and enabling advances in materials. Given the practical limitations of reviewing such a broad area, this review will focus primarily on three approaches to energy harvestingthermal energy harvesting, mechanical-inertial mass-based harvesters, and clothing integrated harvesters. Both systemlevel approaches and the relevant materials considerations are discussed.

For all body-worn harvesting approaches, the problem of energy harvesting can be broken down into three piecescapturing energy from the environment, transducing that energy to electricity, and conditioning the electrical energy for use. (Note, some systems also contain an energy-storage function such as a rechargeable battery or a supercapacitor.) This process is illustrated in Figure 1. Thermal energy harvesting utilizes the temperature difference between the human body and the ambient. The "capture mechanism" would be a heat spreader that touches the skin and a heatsink in contact with the ambient. The heat spreader and sink direct heat flow through the thermoelectric (TE) elements and should be designed to ensure optimal temperature drop across the TE elements, which are the transducing material. This article discusses the design of capture mechanisms and transducer materials, while devoting minimal attention to conditioning electronics.

\section{Thermal energy harvesting System considerations}

The transduction material for thermal energy harvesting for on-body applications is often a TE material. TE materials function by converting a temperature difference into an electrical potential. The primary system consideration for thermal 


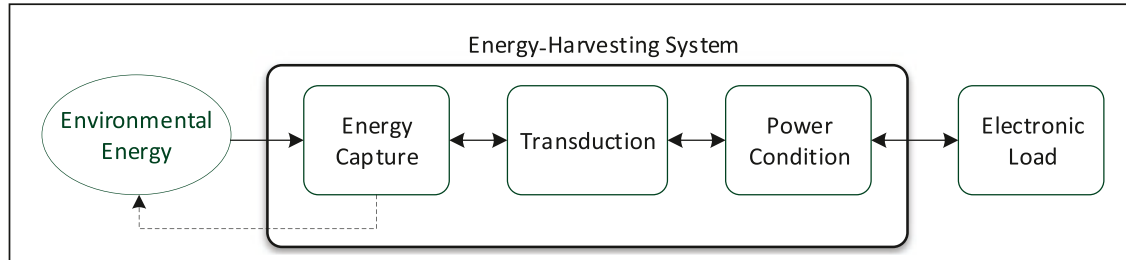

Figure 1. Energy-harvester system diagram.

energy harvesting is to maximize the temperature drop across the TE elements.

A thermal energy-harvesting system can be modeled simply by a thermal-resistive network as in Figure 2. If the thermal resistance (reciprocal of thermal conductance) across the skin and substrate in contact with the skin or the thermal resistance between the heatsink and the air is high relative to the thermal resistance of the TE elements, then most of the temperature drop will occur across those thermal resistances and not generate any power. While the model in Figure 2 is simplified, this basic insight is equally true for more sophisticated models. Suarez et al. ${ }^{8}$ published a thorough analysis of the design of TE energy-harvesting systems for wearable devices and showed that most of the temperature difference between the body's core and the ambient is lost across the skin, substrate, and heatsink rather than the TE elements. Therefore, minimizing the thermal resistances associated with these three elements can have as large an effect on system performance as engineering the TE material itself.

Additionally, the thermal resistance of parallel paths to heat flow, $R_{\mathrm{PAR}}$ in Figure 2, must be maximized or else all the heat will flow around the TE elements rather than through them. This parallel path represents heat flowing in the space between the TE elements. If this space is air, $R_{\mathrm{PAR}}$ will be high, and the associated losses will be small. However, if this space is filled with an elastomer, for example, as might be appropriate for flexible systems, the parallel heat loss can be significant. ${ }^{8}$
Thermal energy-harvesting systems targeting wearable applications are prevalent in the scholarly literature in both rigid ${ }^{7,13-15}$ and flexible ${ }^{1,9,16-18}$ form factors. Bahk et al. ${ }^{19}$ have reviewed TE energy harvesters for wearable applications with a focus on flexible materials. Power densities of the many reviewed publications vary widely, but are all less than $100 \mu \mathrm{W} / \mathrm{cm}^{2}$. To achieve even tens of $\mu \mathrm{W} / \mathrm{cm}^{2}$, bulky rigid heatsinks are necessary. Suarez et al. ${ }^{8}$ conducted a similar study and demonstrated power densities of $10-100 \mu \mathrm{W} / \mathrm{cm}^{2}$, depending on air velocity with a rigid $6 \mathrm{~cm}^{2}$ heat spreader. In order to overcome the need for large and rigid heatsinks, some researchers are investigating thin and flexible nanostructured heatsinks. ${ }^{1}$ Such systems may be able to generate power on the order of hundreds of $\mu \mathrm{W} / \mathrm{cm}^{2}$ in flexible systems.

\section{Material considerations}

The efficiency of a TE device depends on the material's figure of merit (FOM): $Z T=\frac{S^{2} \sigma}{\kappa}$,

where $S$ is the Seebeck coefficient, $\sigma$ is the electrical conductivity, and $\kappa$ is the thermal conductivity. Body-worn TE devices should have peak efficiencies near room temperature, with high and matched $Z T$ for both $n$-type and $p$-type elements (see Figure 2). Given the high input and output thermal resistances of wearable devices, reducing the thermal conductivity of the TE elements has a much larger effect on output power than improving the material FOM $(Z T)$. In practice, lower $\kappa$ is achieved by reducing phonon contributions to thermal conductivity by developing strong scattering from grain boundaries, phase boundaries, and incorporated glassy regions. ${ }^{20,21}$ Microstructure on the nanometer-length scale is most effective. Such fine-scale microstructures can be achieved via a number of routes, including microwave processing and incorporation of second phases.

Although in principle, fine-grained microstructures should produce high fracture toughness, in many cases, cracks and porosity complicate fabrication of the tall, thin legs helpful to maintaining a useful temperature difference between the skin and ambient without excessively clunky heatsinks. This drives work on improving processing of the TEs.

A comparison of TE materials reveals that $\mathrm{Bi}_{2} \mathrm{Te}_{3}$-based materials are well suited for on-body harvesting, as their $Z T$ value peaks near room temperature. ${ }^{21}$ Significant progress has been made in developing nanostructured $p$-type TEs with high performance. However, there are fundamental challenges in making matching $n$-type TEs. First, $\mathrm{Bi}_{2} \mathrm{Te}_{3}$ suffers from lower number of electron pockets near the conduction-band edge compared with
Figure 2. (a) Drawing illustrating a body-worn thermoelectric (TE) energy harvester. (b) Equivalent resistive network, where $T_{\mathrm{C}}$ and $T_{\mathrm{H}}$ are the temperatures of the air and body, respectively, and $R_{\mathrm{C}}, R_{\mathrm{TE}}$, and $R_{\mathrm{H}}$ are the thermal resistances of the heatsink, TE elements, and heat spreader in contact with the skin, respectively. $R_{\mathrm{PAR}}$ is the thermal resistance of the material (usually air) in between the TE elements. The blue and pink TE elements denote $n$ - and $p$-type materials, respectively. 
the number of hole pockets in the $p$-type alloy, reducing the Seebeck coefficient, and second, there is more anisotropy in the TE properties of $n$-type $\mathrm{Bi}_{2} \mathrm{Te}_{3}$ than in the $p$-type material; thus, random polycrystals degrade the values for $S^{2} \sigma{ }^{20,21}$ As $S^{2} \sigma$ drops more rapidly than $\kappa$ in $n$-type $\mathrm{Bi}_{2} \mathrm{Te}_{3}$, the result is a net loss in efficiency.

Additional considerations for wearable energy harvesters include flexibility, good thermal contact to both skin and air, and the need to obtain an output voltage that is high enough to enable efficient boost conversion for charging the battery. In particular, either the TE or its package should be flexible to maintain intimate thermal contact with the skin, such that the hot junction temperature can be maintained, preferably without imposing an uncomfortable mechanical pressure or a propensity for sweating underneath the TE. Likewise, good thermal contact with air and a finite airflow over the device are helpful in increasing the generated power, as seen in Figure 3. ${ }^{22,23}$ The figure shows a flexible device in which the TE elements are embedded in a polymer package, using liquid-metal contacts. Figure $3 \mathrm{~d}$ demonstrates that the measured (and modeled) output voltage, power, and temperature drop across the TE can increase as the air velocity over the TE generator rises.

Finally, the efficiencies of many DC-DC boost converters drop off substantially at voltages below $20-50 \mathrm{mV}$. As a result, it is important to be able to use enough legs that the voltages can add to high enough levels, without having so
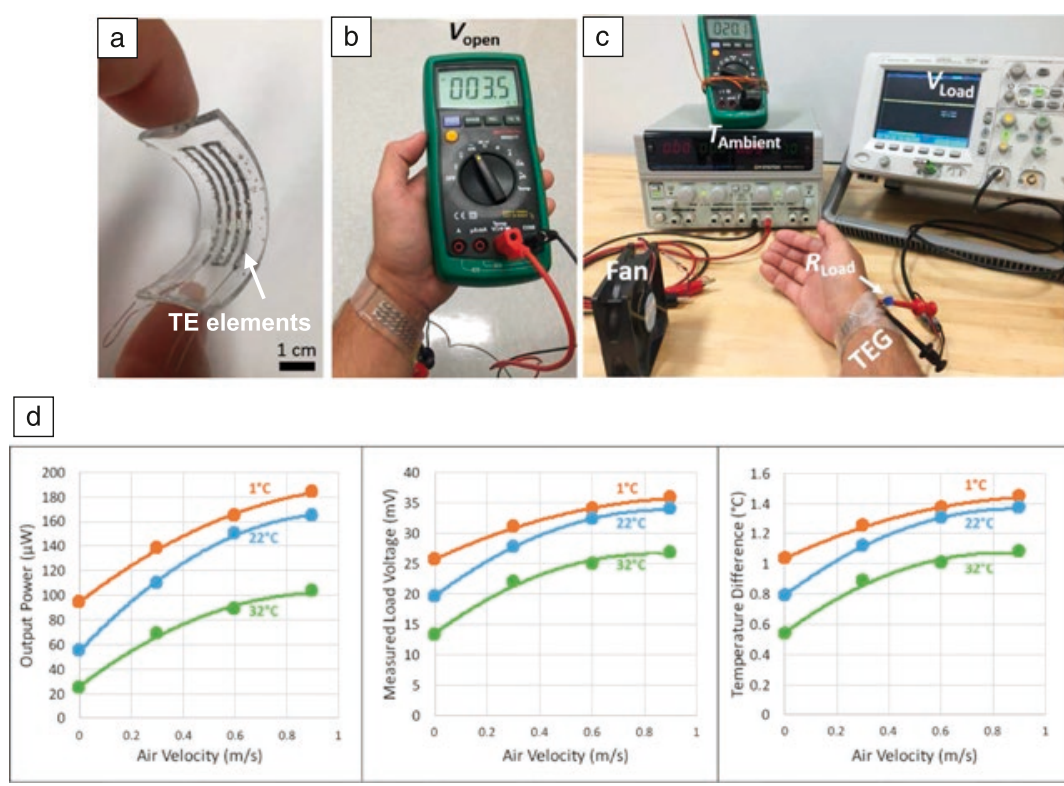

Figure 3. (a) Flexible thermoelectric energy generator (TEG) using liquid-metal contacts on thermoelectric (TE) elements, (b) measurement of open-circuit voltage on-body, (c) experimental setup for measurements as a function of airflow, and (d) measured voltage, power, and temperature drop across the TE elements for a body-worn TE harvester. From (d), it is apparent that as the air velocity over the TE increases, it becomes easier to maintain a temperature gradient $(\Delta T)$ over the TE elements. As a result, the measured voltage over the load and power level rises. Reprinted with permission from Reference 23. () 2017 ICT. Note: $V_{\text {Load, }}$, voltage on the load; $T_{\text {Ambient }}$, ambient temperature; $V_{\text {open }}$, open-circuit voltage; $R_{\text {Load }}$, load resistance. (a-c) Reproduced with permission from Reference 22. () 2017 Elsevier. many that the legs provide a thermal short-circuit between the body and the air.

It should be noted that for normalizing performance of TE materials and devices, the convention is to divide by the active area of the TE module; this is often much smaller than

\section{Inertial energy harvesting System considerations}

There are generally two approaches to harvesting energy from the mechanical motion of the human body. In one approach, vesters." The other approach is to use human motion to excite another inertial mass. The kinetic energy of this inertial mass is then converted to electrical energy by means of a transducer.

The first goal of an inertial energy harvester is to maximize the amount of energy transferred from the environment to an inertial mass. This is the energy capture mechanism. Vibration energy harvesters typically maximize energy captured through the use of resonant linear mechanical oscillators. ${ }^{24-26}$ However, human motion is more difficult to capture than typical vibrations because it is slow, often nonperiodic, and occurs along all three linear and rotational axes. Several basic mechanical architectures for the energy capture system have been proposed, including eccentrically weighted rotors with ${ }^{27}$ and without a restoring spring, ${ }^{4,28-34}$ linear slides or oscillators, ${ }^{5,35-39}$ and a spherical magnet rolling inside a spherical cavity. ${ }^{40,41}$ (See Figure 4.) Each design has its advantages, but the eccentric rotor seems to be the most prevalent and has the advantage that it can be excited by linear or rotational motion about any axis and it responds well to slow motions.

The second goal of an inertial energy harvester is to transduce the kinetic energy of the inertial mass into electrical energy. The design of the capture mechanism does not necessarily determine the type of transducer. For example, eccentric rotor-based harvesters have been demonstrated with piezoelectric, ${ }^{4,32,34}$ electromagnetic, ${ }^{28-30,33}$ and electret-based electrostatic ${ }^{31}$ transducers. The function of the transducer is to convert kinetic energy to electrical energy at the right rate. A transducer with a higher level of coupling (e.g., higher piezoelectric FOM, higher flux density magnets) will convert energy at a higher rate. From the perspective of a purely mechanical system, this higher rate of energy transfer appears as extra damping (or frictional loss). It is important to point out that there is an optimal rate of energy transduction or electromechanical coupling. If it is too high, the inertial mass can become overly damped 


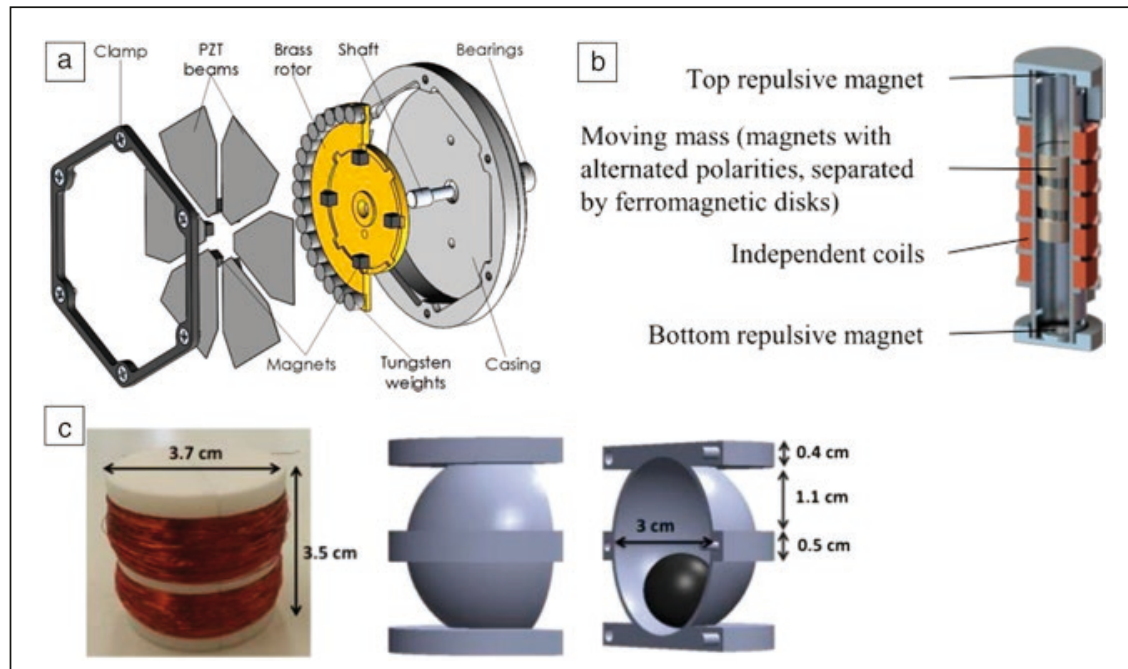

Figure 4. Wearable inertial energy-harvester architectures: (a) eccentric rotor, ${ }^{32}$ (b) linear slide, ${ }^{39}$ and (c) spherical magnet in spherical cavity. ${ }^{41}$ Note: $\mathrm{PZT}$, lead zirconate titanate, $\mathrm{Pb}\left(\mathrm{Zr}_{0.52} \mathrm{Ti}_{0.48}\right) \mathrm{O}_{3}$.

piezoelectric volume all affect the power level attained. It is also imperative that the material have a low dielectric loss at the frequencies for harvesting, such that all of the available power can be extracted via the circuit, rather than dropping across the material.

Priya et al. ${ }^{44}$ describe how energy-harvesting FOM scales with $d_{33} \times g_{33}=\frac{d_{33}^{2}}{\varepsilon_{33}}$, where $d_{33}$ is the piezoelectric charge coefficient, $g_{33}$ the piezoelectric voltage coefficient, and $\varepsilon_{33}$ the relative permittivity, written in matrix notation for bulk materials compressed parallel to the polar axis. For thin films, where the strain coefficients are typically better known than the stress coefficients, the analogous term is $e_{31, \mathrm{f}} \times h_{31, \mathrm{f}}=\frac{e_{31, \mathrm{f}}^{2}}{\varepsilon_{33}}$ for a thin film ${ }^{45}$ with top

and not move much. If the coupling is too low, not enough of the energy captured by the mass gets converted to electricity. It is far more common for the transducer to provide too little coupling (this is called an undercoupled system), and thus, material improvements to the transducer usually (although not always) have the effect of improving generated power by increasing the level of electromechanical coupling.

Demonstrated power densities for wearable inertial energy harvesters range from single-digit $\mu \mathrm{W} / \mathrm{cm}^{3}{ }^{4,31}$ to 150-180 $\mathrm{\mu W} / \mathrm{cm}^{3} .{ }^{37}$ Mitcheson et al. ${ }^{42}$ developed, in an analytical study, a theoretical upper bound on power density of $1 \mathrm{~mW} / \mathrm{cm}^{3}$ under an assumed excitation of $1 G(G=$ gravitational acceleration $=9.81 \mathrm{~m} / \mathrm{s}^{2}$ ) at $1 \mathrm{~Hz}$. These conditions would correspond to vigorous walking. They assumed a linear slide architecture with generous inertial properties. Xue et al. ${ }^{43}$ followed a similar approach and found an upper bound of hundreds of microwatts under a walking excitation for a wrist-mounted device. While these upper bounds do not necessarily apply to all architectures, demonstrated devices are well below them, a fact that indicates significant room for improvement through both innovative system design and improvements in transducer materials and technologies.

As a final note, readers must be careful about comparing the power output of one type of device to another, and demonstrated power outputs to theoretical upper-bound estimates. The excitation conditions for reported power generated vary widely from slow walking ${ }^{43}$ to running, ${ }^{4}$ to shaking with one's hand, ${ }^{35}$ to $17 \mathrm{G}$ vibration excitations. ${ }^{37}$ In the authors' opinion, a representative standard test sorely needs to be developed for accurate and relevant benchmarking of wearable energy harvesters.

\section{Material considerations-Piezoelectric}

In choosing piezoelectric materials for on-body harvesting, the mechanical excitation mode, the product of the piezoelectric charge and voltage coefficients, achievable strain, and and bottom electrodes in a flexural harvester. Again, it is essential that the device generate voltages large enough to be efficiently converted by the rectification electronics, which is easier for voltages $>0.25 \mathrm{~V}$. This is trivial in the case of bulk ceramics (where the opposite problem of inconveniently high voltages is regularly encountered), but is more challenging in thin films. As an alternative to top and bottom electrodes, higher voltages can often be achieved using interdigitated top electrodes on the film, although at the expense of the current. ${ }^{46}$

Two key approaches have been taken to increasing the FOM. Increasing $e_{31, \mathrm{f}}$ has been achieved without rapidly increasing relative permittivity in modified AIN compounds such as $\mathrm{Al}_{1-x} \mathrm{Sc}_{x} \mathrm{~N}$. Here, the low base permittivity counterbalances the comparatively low piezoelectric responses. In perovskite ferroelectrics, the largest piezoelectric responses are achieved in [001]-oriented domain engineered crystals, oriented ceramics, or thin films. However, these compounds typically have large relative permittivities. Thus, to increase the FOM for energy harvesting, the permittivity can be decreased by applying residual stresses that force the polarization out-of-plane, ${ }^{47}$ strongly imprinting the film to produce a strong internal DC bias, ${ }^{48}$ or incorporating porosity. A comparison of FOMs for various thin-film materials is shown in Figure 5. ${ }^{47-55}$

\section{Material considerations-Triboelectric}

As an alternative to piezoelectric energy harvesting, electromagnetic, electrostatic, and triboelectric modalities are also possible. Electromagnetic devices are of particular value when the system size is large (e.g., $\left.>1 \mathrm{~cm}^{3}\right) .{ }^{56}$ While electrostatic generators can readily be miniaturized, they require a priming charge from a power supply; therefore, they may not always be suited to wearable applications.

Triboelectric devices have recently been reported to be of interest for body harvesting. Fundamentally, this mechanism relies on friction to generate opposite electric charges 


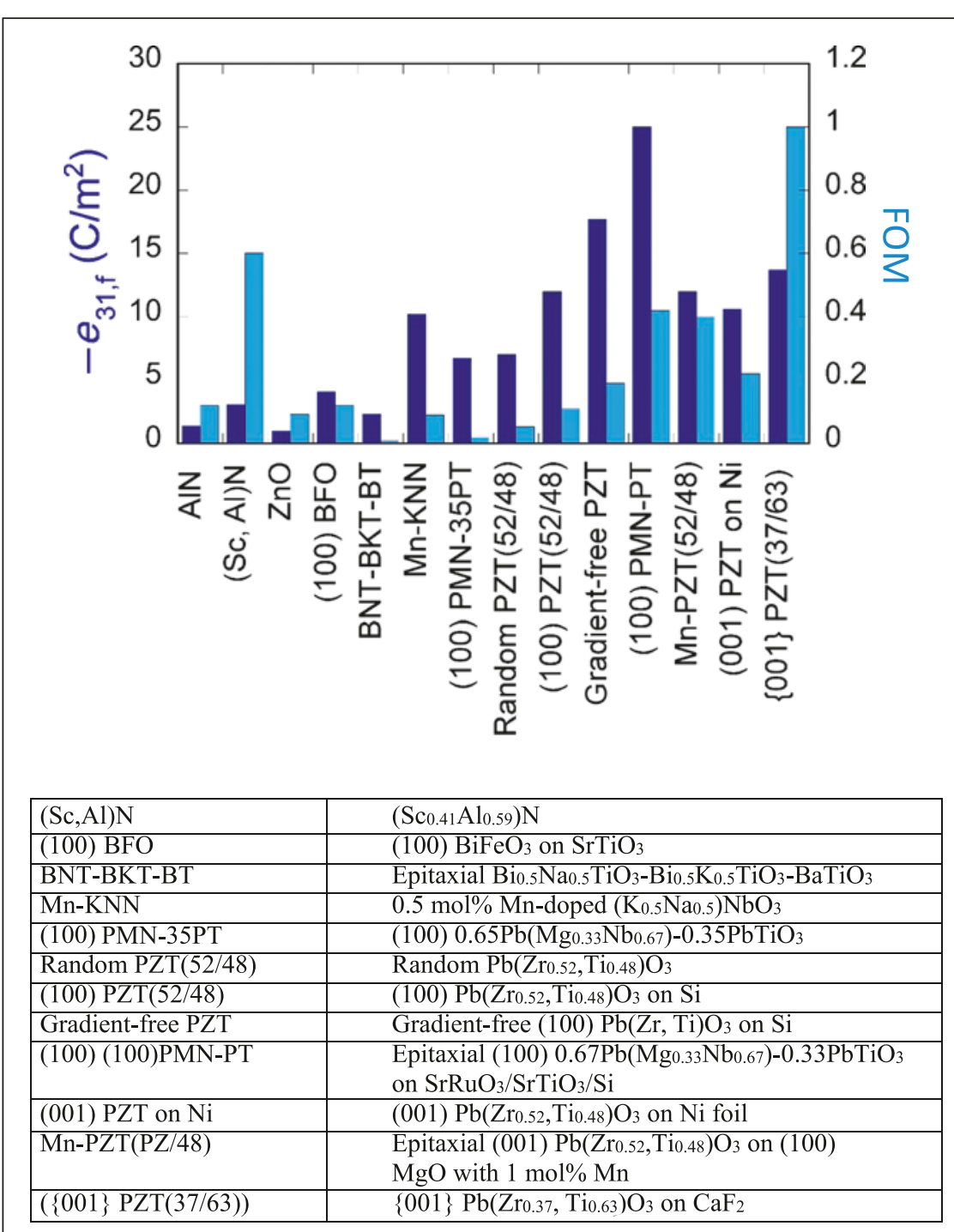

Figure 5. Comparison of piezoelectric coefficients and energy-harvesting figures of merit (FOMs) for a series of piezoelectric films. To date, the highest FOMs for kinetic energy harvesting have been achieved in doped AIN compounds and c-domain perovskite films.

Note: $e_{31, f}$, piezoelectric charge coefficient for thin film. ${ }^{47-55}$

clothing-integrated harvesters get their power from direct interaction with the body, rather than by coupling the energy to an intermediate inertial mass. This energy could come from joint bending, ${ }^{59-61}$ direct force such as tapping or pushing on the clothing, ${ }^{62}$ friction between the relative motion of two components of clothing, ${ }^{63-65}$ or chest expansion. ${ }^{66}$

Much work has focused on developing flexible and stretchable transducer materials ${ }^{63,64,67-70}$ and integrating transducers into clothing. ${ }^{65,69}$ Material issues are covered in more detail in the following section. Here, we simply note that transducers are generally piezoelectric, ${ }^{62,69,70}$ electrostatic, ${ }^{68}$ or triboelectric. ${ }^{63-65}$ There are fewer papers demonstrating clothing-integrated harvesting systems. Yang and Yun ${ }^{59}$ demonstrated a flexible semitubular piezoelectric shell structure-based harvester that can be put into a finger or elbow joint harvester and that yields $2.18 \mathrm{~mW} / \mathrm{cm}^{2}$ from being cyclically bent by $80^{\circ}$ at $3.3 \mathrm{~Hz}$ (see Figure 6). Yun et al. ${ }^{70}$ demonstrated a stretchable device incorporating piezoelectric helices wrapped around a stretchable core (see Figure 6). This device produced $0.3 \mathrm{~mW} / \mathrm{cm}^{3}$ from applying a cyclical strain of $60 \%$ at $4 \mathrm{~Hz}$. Padasdao et al. ${ }^{66}$ demonstrated an average power of $0.072 \mathrm{~mW}$ from a chest band that, under expansion from breathing while walking, turns a DC brushed motor used as a generator. While power densities of $2.18 \mathrm{~mW} / \mathrm{cm}^{2}$ and $0.3 \mathrm{~mW} / \mathrm{cm}^{3}$ seem promising, the excitations do not seem to correlate to any normal human motion.

Starner and Paradiso, ${ }^{3}$ and Riemer and Shapiro ${ }^{71}$ both studied the mechanics of body motion to estimate how much power the body exerts during different motions. The results relevant to clothing integrated harvesters from

on different surfaces. If these charges can be collected on electrodes, high instantaneous powers can be achieved by this mechanism. ${ }^{57}$ It is less clear that the average power levels will be adequate for many applications. From a materials perspective, the key attributes for a wearable triboelectric harvester are a comparatively rough surface to maximize the friction, abrasion-resistance to prevent wear, the ability to produce large-area parts to facilitate integration into garments, and some level of stretchability or flexibility for comfort. ${ }^{58}$ Many papers report on the use of abundant fibers such as cellulose or silk as key constituents of a wearable harvester.

\section{Mechanical clothing-integrated harvesters System considerations}

The primary distinction between inertial harvesters and clothing-integrated harvesters for the purposes of this article is that these studies are summarized in Table $\mathbf{I}$.

The amount of power available via knee bending and ankle motion, for example, is quite large - tens of watts. However, as previously summarized, reported power outputs are far below what is possible, indicating much space for innovation. The forces available from joint bending can be large, however, coupling to those forces to generate power generally results in very tight-fitting clothing that may not be comfortable and may feel restrictive to the user. Chest expansion is a good example. Because we are always breathing, accessing the power available from chest expansion could be a reliable way to power smart clothing. However, the extra compression around the chest required to couple the transducer (i.e., flexible piezoelectric material, ${ }^{72}$ or a small motor ${ }^{66}$ ) to chest expansion can result in an unacceptably restrictive garment or chest band. 


\section{a}

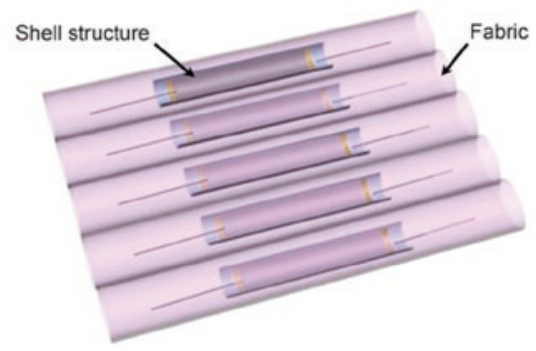

$\mathrm{b}$
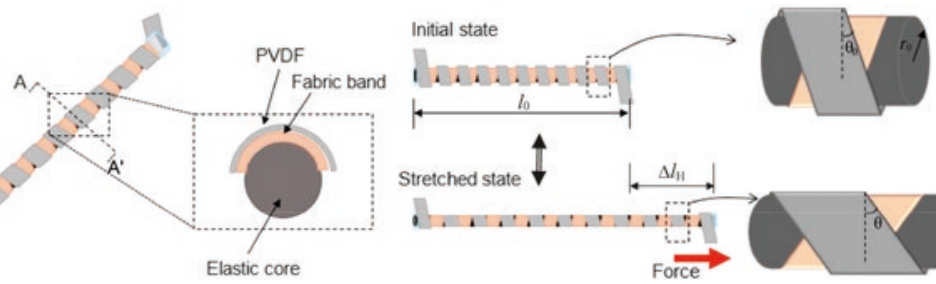

Elastic core

Figure 6. (a) Piezoelectric shell structure that can generate power from being placed in fabric on the elbow or finger. Reprinted with permission from Reference 59. (C) 2012 Elsevier. (b) Wearable harvester incorporating helical piezoelectric strips around a stretchable core. ${ }^{70}$ When the device is stretched, the helical piezoelectric structure experiences a torsional and longitudinal tensile stress, which produces an electrical potential. Note: PVDF, poly(vinylidene fluoride), $110-\mu \mathrm{m}$ thick; $I_{0}$, initial harvester length; $\Delta I_{\mathrm{H}}$, change in harvester length; $\theta_{0}$, winding angle of the PVDF strap; $\theta$, deflected angle of the PVDF strap after stretching; $r_{0}$, initial core radius; $r$, final core radius. functional fibers ${ }^{73}$ or spray-coating preexisting fabrics. ${ }^{74}$ This provides the inherent flexibility associated with textiles.

Piezoelectric polymers are lightweight, tough, and available in large-area formats, and can be formed into complex shapes. ${ }^{75} \mathrm{Of}$ these, commercially available ones include polyvinylidene fluoride (PVDF) and PVDFtrifluoroethylene copolymers. Conventional bimorph structures have been made using PVDF as the active layer of a bending-based harvester that could readily be integrated into clothing. ${ }^{76}$ PVDF typically tolerates much higher strain levels (up to $3 \%$ ) than ceramic materials such as those shown in Figure 5, thus allowing higher powers to be extracted even though the energy-harvesting FOM is smaller.

Alternative approaches to achieving flexible piezoelectric harvesters include use of flexible substrates such as metal foils, ${ }^{77}$ or transferring piezoelectric layers onto polymers. ${ }^{78}$ The latter can be accomplished through the use of a sacrificial layer underneath the piezoelectric layer. ${ }^{79} \mathrm{MgO}, \mathrm{Si}$, and $\mathrm{ZnO}$
Some motions are energetic, such as hip motion, but difficult to couple because of the small changes in joint angle. So, while there is a lot of potential power that could be generated from clothing, doing so in a comfortable and practical way has not been well demonstrated. Finally, system-level challenges include the difficulty of integrating electromechanical transducers with fabric and finding transducer materials with the required level of stretchiness to ensure user comfort.

\section{Material considerations}

Several approaches can be taken in creating flexible or stretchable harvesters. As previously described, there is an extensive research effort now on integrating triboelectricity into large-scale garments through means such as weaving have all been utilized for the sacrificial layer. The latter two, in particular, have etchants that are selective with respect to a number of high FOM energy-harvesting materials, facilitating transfer to the flexible substrate with a minimum of damage.

\section{Conclusions}

On-body energy harvesting can take many forms. This article has sought to discuss system and materials considerations for three classes of on-body energy harvesters - thermal energy harvesters, inertial energy harvesters, and clothing integrated (or flexible) energy harvesters. The article also briefly reviewed the state of the art for each class of energy harvester. In all cases, there has been a large amount of activity recently in the research community and significant progress. However, the performance of current system demonstrations is well

\section{Table I. Summary of power consumed by human body during various actions.}

\begin{tabular}{|l|c|c|}
\hline Motion & Power (W) & Reference \\
\hline Chest expansion & 0.83 & 3 \\
\hline Finger motion & $0.007-0.019$ & 3 \\
\hline Footfalls & 67 & 3 \\
\hline Heel strike & $2-20$ & 71 \\
\hline Ankle motion (walking) & 67 & 71 \\
\hline Knee motion (walking) & 37 & 71 \\
\hline Hip motion (walking) & 38 & 71 \\
\hline Elbow motion (walking) & 2.1 & 71 \\
\hline Shoulder motion (walking) & 2.2 & 71 \\
\hline
\end{tabular}
possible. Thus, there is significant space, and need, for innovation at both the system and materials levels.

\section{Acknowledgments}

The authors gratefully acknowledge the support of the National Science Foundation (NSF) ASSIST Nanosystems ERC under Award No. EEC-1160483. S.T.M. also acknowledges NSF Award No. CNS-1646399. 


\section{References}

1. V. Misra, A. Bozkurt, B. Calhoun, T. Jackson, J.S. Jur, J. Lach, B. Lee, J. Muth, J.Ö Oralkan, M. Öztürk, S. Trolier-McKinstry, Proc. IEEE 103, 665 (2015). 2. L.M. Castano, A.B. Flatau, Smart Mater. Struct. 23, 053001 (2014).

3. T. Starner, J. Paradiso, in Low-Power Electronics, C. Piguet, Ed. (CRC Press, Boca Raton, FL, 2004), pp. 45-1-45-32.

4. P. Pillatsch, E.M. Yeatman, A.S. Holmes, Sens. Actuators A 206, 178 (2014). 5. M. Renaud, P. Fiorini, R. van Schaijk, C. van Hoof, Smart Mater. Struct. 21, 49501 (2012).

6. R. Rantz, T. Xue, Q. Zhang, L. Gu, K. Yang, S. Roundy, J. Phys. Conf. Ser. 773, 12076 (2016).

7. I. Stark, presented at the Wireless Health 2012 Conference, San Diego, October 23-25, 2012, pp. 3-4.

8. F. Suarez, A. Nozariasbmarz, D. Vashaee, M.C. Öztürk, Energy Environ. Sci. 9. 2099 (2016)

9. A.R.M. Siddique, R. Rabari, S. Mahmud, B. Van Heyst, Energy 115, 1081 (2016). 10. J.A. Paradiso, T. Starner, IEEE Pervasive Comput. 4, 18 (2005)

11. A. Bramhanand, M. Rahman, Y. Bae, H. Kim, Solid-State Sensors, Actuators, and Microsystems Workshop (Hilton Head, SC, June 3-7, 2012), p. 497.

12. T. Krupenkin, J.A. Taylor, Nat. Commun. 2, 448 (2011).

13. V. Leonov, R.J.M. Vullers, J. Electron. Mater. 38, 1491 (2009).

14. V. Leonov, IEEE Sens. J. 13, 2284 (2013).

15. V. Leonov, R.J.M. Vullers, J. Renew. Sustain. Energy 1, 62701 (2009).

16. M.-K. Kim, M.-S. Kim, S. Lee, C. Kim, Y.-J. Kim, Smart Mater. Struct. 23, $105002(2014)$

17. S.J. Kim, J.H. We, B.J. Cho, Energy Environ. Sci. 7, 1959 (2014).

18. C. Wan, R. Tian, A.B. Azizi, Y. Huang, O. Wei, R. Sasai, S. Wasusate, T. Ishida K. Koumoto, Nano Energy 30, 840 (2016).

19. J.-H. Bahk, H. Fang, K. Yazawa, A. Shakouri, J. Mater. Chem. C 3, 10362 (2015) 20. M. Hyland, H. Hunter, J. Liu, E. Veety, D. Vashaee, Appl. Energy 182, 518 (2016)

21. B. Poudel, Q. Hao, Y. Ma, Y. Lan, A. Minnich, B. Yu, X. Yan, D. Wang, A. Muto D. Vashaee, X. Chen, J. Liu, M.S. Dresselhaus, G. Chen, Z. Ren, Science $\mathbf{3 2 0}$ 634 (2008).

22. F. Suarez, D.P. Parekh, C. Ladd, D. Vashaee, M.D. Dickey, M.C. Öztürk, Appl. Energy 202, 736 (2017).

23. Y. Sargolzaeiaval, T. Neumann, F. Suarez, V.P. Ramesh, D.P. Parekh, D. Vashaee, M. Dickey, M.C. Öztürk, "Flexible Thermoelectric Energy Harvesters Using Bulk Thermoelectric Legs and Low-Resistivity, Stretchable Liquid Metal Interconnects," presented at the International Conference on Thermoelectrics, ICT 2017, Pasadena CA, July 28-August 3, 2017.

24. M. El-hami, P. Glynne-Jones, N.M. White, M. Hill, S. Beeby, A.D. Brown, J.N. Ross, Sens. Actuators A 92, 335 (2001).

25. P.D. Mitcheson, T.C. Green, E.M. Yeatman, A.S. Holmes, J. Microelectromech. Syst. 13, 1 (2004)

26. S. Roundy, P.K. Wright, Smart Mater. Struct. 13, 1131 (2004).

27. E.M. Yeatman, J. Mech. Eng. Sci. 222, 27 (2008).

28. M. Hayakawa, "Electronic Wristwatch with Generator," US Patent $5,001,685$ (1989).

29. M. Lossec, B. Multon, H. Ben Ahmed, MELECON 2010-2010 15th IEEE Mediterr. Electrotech. Conf. (2010), pp. 1516-1521.

30. E. Romero, M.R. Neuman, R.O. Warrington, 2011 IEEE 24th Int. Conf. Micro Electro Mech. Syst. (2011), p. 1325.

31. J. Nakano, K. Komori, Y. Hattori, Y. Suzuki, J. Phys. Conf. Ser. 660, 12052 (2015)

32. T. Xue, H.G. Yeo, S. Trolier-McKinstry, S. Roundy, Transducers'17 (Kaohsiung, Taiwan, 2017), pp. 375-378.

33. M.A. Halim, R. Rantz, Q. Zhang, L. Gu, K. Yang, S. Roundy, Transducers'17 (Kaohsiung, Taiwan, 2017), pp. 1863-1866.

34. R. Lockhart, P. Janphuang, D. Briand, N.F. de Rooij, 2014 IEEE 27th Int. Conf. Micro Electro Mech. Syst. (2014), pp. 370-373.

35. M.A. Halim, J.Y. Park, Sens. Actuators A 229, 50 (2015).

36. M. Geisler, S. Boisseau, P. Gasnier, J. Willemin, C. Gobbo, G. Despesse, I. Ait-Ali, S. Perraud, Smart Mater. Struct. 26, 105035 (2017).

37. A. Haroun, I. Yamada, S. Warisawa, Sens. Actuators A 224, 87 (2015).

38. T.A. Shastry, M. Geier, A. Smith, "Kinetic Energy Harvesting Methods and Apparatus," US Patent US20160020682 A1 (2015).

39. M. Geisler, S. Boisseau, M. Perez, I. Ait-Ali, S. Perraud, J. Phys. Conf. Ser. 773, 012044 (2016).

40. Y. Rao, S. Cheng, D.P. Arnold, J. Micromech. Microeng. 23, 114012 (2013). 41. Y. Rao, K.M. McEachern, D.P. Arnold, J. Phys. Conf. Ser. 476, 012011 (2013).

42. P.D. Mitcheson, E.M. Yeatman, G.K. Rao, A.S. Holmes, T.C. Green, Proc. IEEE 96, 1457 (2008).

43. T. Xue, X. Ma, C. Rahn, S. Roundy, J. Phys. Conf. Ser. 557, 12090 (2014). 44. H. Kim, Y. Tadesse, S. Priya, Energy Harvesting Technologies, S. Priya, D. Inman, Eds. (Springer Science and Business Media, New York, 2009), pp. 3-39. 45. C.B. Yeager, S. Trolier-McKinstry, J. Appl. Phys. 112, 74107 (2012).

46. Y.B. Jeon, R. Sood, J.-H. Jeong, S.-G. Kim, Sens. Actuators A 122, 16 (2005).
47. C.B. Yeager, E. Yoshitaka, N. Oshima, H. Funakubo, S. Trolier-McKinstry, J. Appl. Phys. 116, 104907 (2014).

48 S. Trolier-McKinstry, F. Griggio, C. Yaeger, P. Jousse, D. Zhao, S.S.N. Bharadwaja T.N. Jackson, S. Jesse, S.V. Kalinin, K. Wasa, IEEE Trans. Ultrason. Ferroelectr. Freq. Contro/58, 1782 (2011)

49. C.B. Yeager, "PZT Thin Films for Piezoelectric MEMS Mechanical Energy Harvesting," PhD thesis, The Pennsylvania State University, University Park, PA (2015).

50. S.S. Won, J. Lee, V. Venugopal, D. Kim, J. Lee, I.W. Kim, A.I. Kingon, S. Kim, Appl. Phys. Lett. 108, 232908 (2016)

51. F. Calame, P. Muralt, Appl. Phys. Lett. 90, 0629097 (2007)

52. I.G. Mina, H. Kim, I. Kim, S.K. Park, K. Choi, T.N. Jackson, R. L. Tutwiler S. Trolier-McKinstry, IEEE Trans. Ultrason. Ferroelectr. Freq. Contro/54, 2422 (2007). 53. M. Akiyama, K. Umeda, A. Honda, T. Nagase, Appl. Phys. Lett. 102, 021915 (2013). 54. R. Matloub, M. Hadad, A. Mazzalai, N. Chidambaram, G. Moulard, C.S. Sandu, T. Metzger, P. Muralt, Appl. Phys. Lett. 102, 152903 (2013).

55. K. Ujimoto, T. Yoshimura, A. Ashida, N. Fujimura, Appl. Phys. Lett. 100 102901 (2012)

56. K.A. Cook-Chennault, N. Thambi, A.M. Sastry, Smart Mater. Struct. 17 041003 (2008)

57. F.-R. Fan, Z.-Q. Tian, Z. Lin Wang, Nano Energy 1, 328 (2012).

58. Y. Cheng, X. Lu, K. Hoe Chan, R. Wang, Z. Cao, J. Sun, G. Wei Ho, Nano Energy 41, $511(2017)$

59. B. Yang, K.S. Yun, Sens. Actuators A 188, 427 (2012)

60. G. De Pasquale, S.-G. Kim, D. De Pasquale, IEEE/ASME Trans. Mechatron. 21, 565 (2015).

61. M. Lee, C.Y. Chen, S. Wang, S.N. Cha, Y.J. Park, J.M. Kim, L.J. Chou, Z.L. Wang, Adv. Mater. 24, 1759 (2012)

62. A. Almusallam, Z. Luo, A. Komolafe, K. Yang, A. Robinson, R. Torah, S. Beeby, Nano Energy 33, 146 (2017)

63. S.S. Kwak, H. Kim, W. Seung, J. Kim, R. Hinchet, S.-W. Kim, ACS Nano 11, 10733 (2017)

64. X. Pu, L. Li, H. Song, C. Du, Z. Zhao, C. Jiang, G. Cao, W. Hu, Z.L. Wang, Adv. Mater. 27, 2472 (2015).

65. W. Seung, M.K. Gupta, K.Y. Lee, K.S. Shin, J.H. Lee, T.Y. Kim, S. Kim, J. Lin, J.H. Kim, S.W. Kim, ACS Nano 9, 3501 (2015)

66. B. Padasdao, E. Shahhaidar, C. Stickley, O. Boric-Lubecke, IEEE Sens. J. 13, $4204(2013)$

67. D. Yun, K.S. Yun, Electron. Lett. 49, 65 (2013)

68. Y. Eun, D.-S. Kwon, M.-O. Kim, I. Yoo, J. Sim, H.-J. Ko, K.-H. Cho, J. Kim, Smart Mater. Struct. 23, 45040 (2014).

69. W. Wu, S. Bai, M. Yuan, Y. Qin, Z.L. Wang, T. Jing, ACS Nano 6, 6231 (2012) 70. M. Kim, K.-S. Yun, Micromachines 8, 115 (2017)

71. R. Riemer, A. Shapiro, J. Neuroeng. Rehabil. 8, 22 (2011)

72. E. Shahhaidar, B. Padasdao, R. Romine, C. Stickley, O. Boric-Lubecke, Proc Annu. Int. Conf. IEEE Eng. Med. Biol. Soc. EMBS (2013), pp. 3439-3442.

73. Y. Song, J. Zhang, H. Guo, X. Chen, Z. Su, H. Chen, X. Cheng, H. Zhang, Appl. Phys. Lett. 111, 1 (2017)

74. C. Liu, J. Li, L. Che, S. Chen, Z. Wang, X. Zhou, Nano Energy 41, 359 (2017) 75. G.T. Davis, Polymers for Electronic and Photonic Applications, C.P. Wong, Ed. (Academic Press, San Diego, 1993), pp. 435-461.

76. S.S. Won, M. Sheldon, N. Mostovych, J. Kwak, B. Chang, C.W. Ahn, A.I. Kingon, I.W. Kim, S. Kim, S.S. Won, M. Sheldon, N. Mostovych, J. Kwak, Appl. Phys. Lett. 107, 202901 (2015)

77. H.G. Yeo, S. Trolier-McKinstry, J. Appl. Phys. 116, 014105 (2014).

78. T. Liu, M. Wallace, S. Trolier-McKinstry, T.N. Jackson, J. Appl. Phys. 122 164103 (2017).

79. Y. Qi, N.T. Jafferis, K. Lyons, C.M. Lee, H. Ahmad, M.C. McAlpine, Nano Lett 10, $524(2010)$.

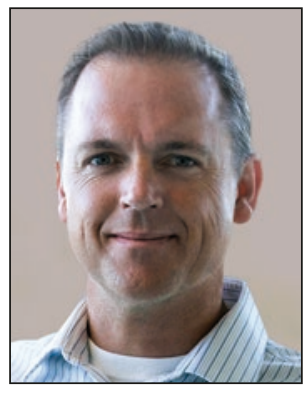

Shad Roundy joined The University of Utah in 2012 as a faculty member in the Department of Mechanical Engineering. He received his PhD degree in mechanical engineering from the University of California, Berkeley, in 2003. He was a senior lecturer at the Australian National University for two years. He worked with startup companies for several years prior to joining The University of Utah. He is the recipient of the DOE Integrated Manufacturing Fellowship, the Intel Noyce Fellowship, and was named by the Massachusetts Institute of Technology's Technology Review as one of the world's top 100 young innovators for 2004. His current research interests include harvesting energy for wireless sensors, particularly from vibrations, acoustics, and human motion. Roundy can be reached by phone at 801-581-4304 or by email at shad.roundy@utah.edu. 


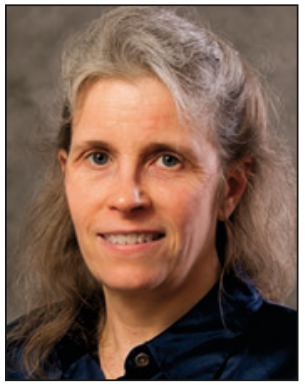

Susan Trolier-McKinstry is the Steward S. Flaschen Professor of Ceramic Science and Engineering and professor of electrical engineering at The Pennsylvania State University (Penn State), where she also serves as the director of the Nanofabrication Facility. She obtained her BS, MS, and PhD degrees in ceramic science and engineering, all from Penn State, and joined the faculty there after graduation. She is a fellow of MRS, IEEE, and The American Ceramic Society, and is an academician of the World Academy of Ceramics. She was president of the Materials Research Society in 2017. Her current research interests include thin films for dielectric and piezoelectric applications. Trolier-McKinstry can be reached by phone at 814-863-8348 or by email at stmckinstry@psu.edu.
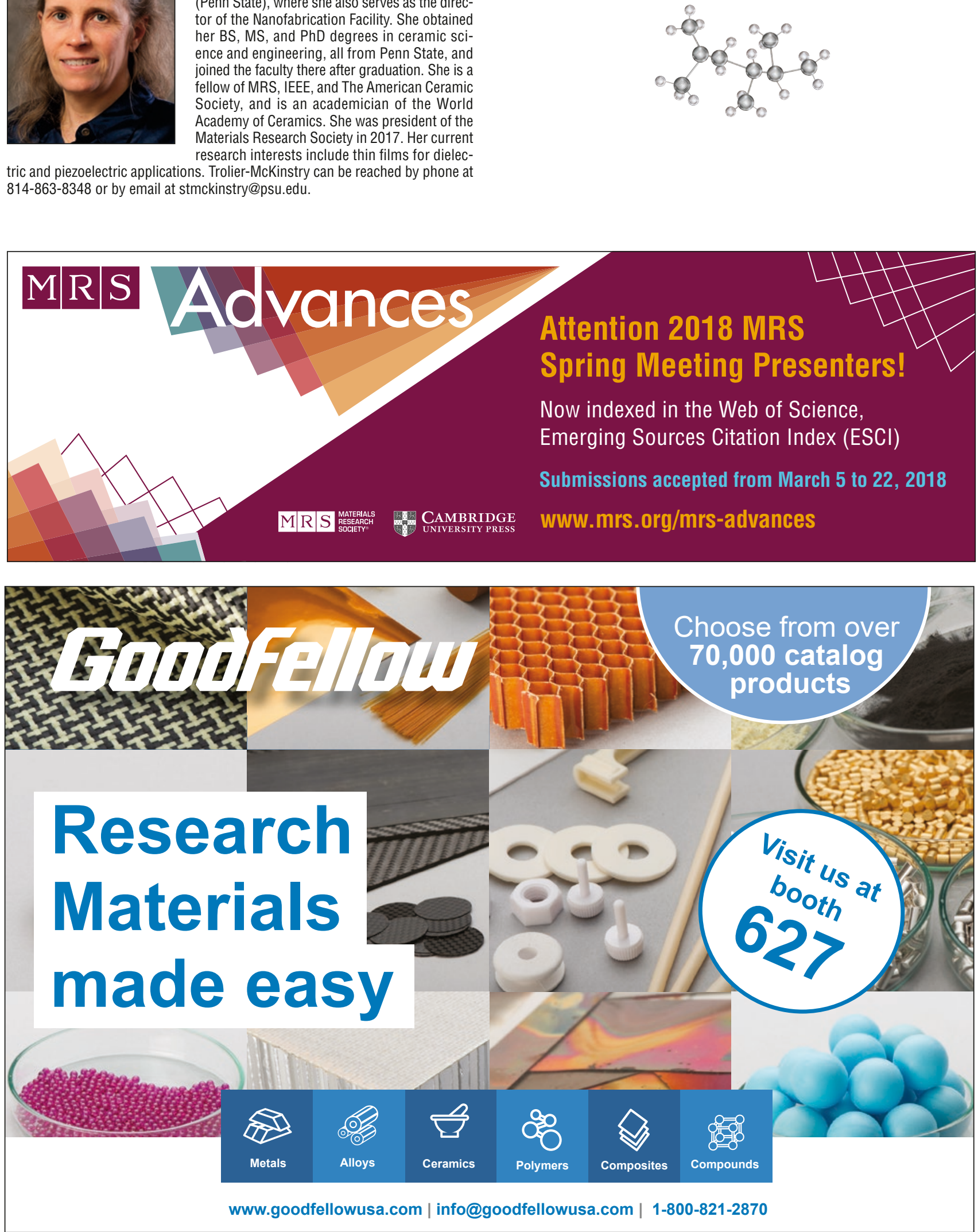